\title{
OAB FINALMENTE VAI PRESTAR CONTAS: DECISÃO DO TCU CORRIGE ERRO HISTÓRICO
}

\author{
Coluna publicada em 13.11.2018: <https://www.conjur.com.br/2018-nov-13/ \\ contas-vista-decisao-tcu-manda-oab-prestar-contas-corrige-erro-historico $>$
}

No último dia $7,{ }^{1}$ o Tribunal de Contas da União tomou uma decisão importante para a transparência e o sistema de controle e fiscalização das contas públicas: assentou que a $\mathrm{OAB}$ deve submeter suas contas ao Tribunal de Contas da União. ${ }^{2}$ Essa decisão corrige um erro histórico, sendo marcante para o Direito Financeiro, uma vez que incorpora ao sistema de fiscalização financeira a única entidade que, apesar de estar entre as que devem prestar contas, nunca o fez e sempre conseguiu se desvencilhar dessa obrigação constitucional.

Diz o artigo 70, parágrafo único, da Constituição, que "prestará contas qualquer pessoa física ou jurídica, pública ou privada, que utilize, arrecade, guarde, gerencie ou administre dinheiros, bens e valores públicos ou pelos quais a União responda, ou que, em nome desta, assuma obrigações de natureza pecuniária”.

Uma redação que não deixa qualquer margem a dúvida sobre a abrangência do sistema de fiscalização financeira da administração pública, que é o mais amplo possível: onde há recursos públicos, atua o sistema de fiscalização das contas públicas.

E não permite que prevaleçam os argumentos que a $\mathrm{OAB}$ vem adotando como verdadeiro "escudo" para se "defender" da ação do TCU. Uma atitude que, além

1 TCU diz que OAB não é imune a controle e manda prestar contas a partir de 2021. ConJur, 7 de novembro de 2018.

2 Voto proferido no processo administrativo instaurado por determinação do subitem 9 de março de 2018 do Acórdão 1.114/2018-TCU-Plenário, nos autos do TC 008.199/2018-3 - Estudo técnico sobre a inclusão ou não da Ordem dos Advogados do Brasil (OAB) como unidade prestadora de contas. 
de contrariar a Constituição, é absolutamente injustificável em um Estado Democrático de Direito, em que a transparência e o dever de prestar contas é a regra, e não exceção. Muito mais condizente com os princípios republicanos seria a $\mathrm{OAB}$ voluntariamente, independentemente de qualquer obrigação constitucional, oferecer suas contas para serem analisadas não somente pelo TCU, mas por toda a sociedade brasileira. E não se esforçar para escapar de seu dever constitucional de prestar contas, como tem reiteradamente feito há décadas.

O tema é há muito discutido - desnecessariamente, uma vez que bastaria um gesto da $\mathrm{OAB}$ de não mais oferecer essa resistência e esse tema nem sequer estaria em pauta -, e muito já foi escrito e debatido a respeito. Sendo assim, mais útil é pontuar os argumentos que têm sido levantados, e rebatê-los um a um, esperando que com isso não restem mais dúvidas a respeito dessa questão. E fica a esperança de que esta seja finalmente sepultada com a histórica decisão do TCU, que mais uma vez demonstra sua altivez na defesa da transparência das contas públicas e faz jus à condição de maior guardiāo do dinheiro público. ${ }^{3}$

\section{A OAB é um "órgão sui generis"}

Argumenta-se que a OAB seria uma instituição sui generis, sem natureza pública, que não integraria a administração indireta da União, o que seria suficiente para colocá-la à margem do sistema de fiscalização financeira. ${ }^{4}$

Uma tese que não se sustenta.

O ministro Bruno Dantas, em seu voto no citado acórdão (nota de rodapé 2), expôs com clareza a questão, com apoio no parecer do Ministério Público de Contas, da lavra do procurador Lucas da Rocha Furtado, e não deixa dúvidas sobre a natureza de autarquia federal da OAB.

Trata-se de um serviço autônomo, criado por lei e com personalidade jurídica (Estatuto da $\mathrm{OAB}$, art. 44), patrimônio e receita próprios (idem, art. 46, caput, 54 , XVI e $55, \S 1^{\circ}$ ), e desempenha atividade típica da administração pública, uma vez que exerce a fiscalização da atividade profissional dos advogados, exercendo poder de polícia administrativa, como fazem todos os demais conselhos profissionais, em uma atividade típica de manifestação do poder soberano do Estado (Constituição, arts. 21, XXIV e 22, XVI).

3 Tribunais de Contas são os guardiōes do dinheiro público, nesta edição, p. 317-322.

4 Nesse sentido há inclusive a decisão do STF na qual se apoia a OAB para sustentar essa tese, proferida na ADI 3.026-4/DF.

5 Vide voto do Min. Bruno Dantas, nota de rodapé 2, p. 9-11. 
É fato que a $\mathrm{OAB}$ tem prerrogativas próprias, que extrapolam a simples atuação no âmbito corporativo da carreira dos advogados e não permitem equipará-la integralmente aos demais conselhos profissionais. Tem funções institucionais de defesa dos interesses da sociedade brasileira, e isso exige que se tenha especial atenção no respeito à sua autonomia e independência. É o caso da iniciativa para propositura de ação direta de inconstitucionalidade e ação declaratória de constitucionalidade (Constituição, art. 103, VII). E é verdade, como se tem sustentado, que tem sido uma voz crítica da sociedade em defesa dos ideais democráticos. No entanto, tais prerrogativas e atuação crítica em nada justificam sua exclusão da categoria de entidade com natureza de autarquia federal, que integra a administração indireta da União, uma vez que uma coisa nada tem a ver com a outra. Não há órgãos com maiores garantias constitucionais de independência que o Poder Judiciário, Ministério Público, os próprios tribunais de contas e tantos outros, e que integram a administração direta, o que afasta por completo qualquer relação de subordinação entre o fato de integrar a administração pública e ter autonomia e independência de qualquer natureza.

Além de inconsistente o argumento que coloca a OAB em um "limbo" jurídico no que se refere à sua natureza jurídica, tentando retirá-la da condição de órgão da administração indireta da União, esse fato não afasta em absoluto o dever de submeter suas contas ao TCU.

Como se vê da redação do texto constitucional, deverá prestar contas "qualquer pessoa física ou jurídica, pública ou privada” (grifo nosso), pouco importando para esse fim, portanto, a sua natureza jurídica, uma vez que o aspecto subjetivo da sujeição à fiscalização é apenas um dos motivos que leva à obrigação de prestar contas.

Importa também o aspecto objetivo, qual seja, a natureza dos recursos envolvidos. Como diz a Constituição - que a OAB tem o dever institucional de defender, e é o que lhe dá argumento para ser um "órgão sui generis" -, deverá prestar contas quem "utilize, arrecade, guarde, gerencie ou administre dinheiros, bens e valores públicos ou pelos quais a União responda”.

E quanto a isso não há dúvidas, não obstante os esforços argumentativos em sentido contrário, como se verá a seguir.

\section{A OAB "não gerencia recursos públicos"}

Outro argumento que vem sendo reiteradamente utilizado refere-se à natureza jurídica da contribuição à $\mathrm{OAB}$, que não seria recurso público. 
A contribuição à $\mathrm{OAB}$ é cobrada com fundamento no artigo 149, inserto no capítulo do sistema tributário nacional da Constituição, que autoriza a União a instituir contribuições de interesse de categorias profissionais, devendo observar o disposto nos artigos 146, III (normas gerais em matéria tributária) e 150, I (princípio da legalidade) e III (princípios da irretroatividade e anterioridade), cobrança essa que não é feita diretamente pela União, mas tem sua capacidade tributária ativa delegada à $\mathrm{OAB}$.

O mesmo ocorre com as demais categorias profissionais, cujos órgãos de classe também cobram as referidas contribuiçôes, como os diversos conselhos de fiscalização das atividades profissionais, estando assentada a natureza de autarquias corporativas cujas contribuições tem natureza tributária. ${ }^{6}$

A clareza do texto constitucional não deixa qualquer margem a outra interpretação. ${ }^{7} \mathrm{O}$ mundo jurídico, no entanto, sempre pode surpreender e permite encontrar argumentos e decisões que sustentam todas as posições. Fica com o intérprete o encargo de aceitá-los - ou não.

$\mathrm{A} \mathrm{OAB}$ já teve decisões favoráveis à tese de que suas contribuições não têm natureza tributária. O fundamento foi o seguinte: como os tributos devem ser submetidos ao regime jurídico tributário, devendo obedecer aos princípios da tipicidade, tendo seus elementos material (hipótese de incidência) e subjetivo, quantitativo, espacial e temporal previstos na norma que o institui, e isso não ocorre no caso da $\mathrm{OAB}$, que tem suas contribuições fixadas à margem dessas regras, isso levaria à conclusão de que tenha natureza de contribuição de caráter associativo. ${ }^{8} \mathrm{O}$ que se permite compreender desse raciocínio é que, se a Constituição determina que devam ser cumpridas determinadas regras, mas elas não são cumpridas, então a Constituição não se aplica ao caso. Um verdadeiro "salto triplo carpado hermenêutico", para usar as palavras do ministro Carlos Ayres Brito (STF, RE 630.147).

\section{Ter as contas fiscalizadas pelo TCU prejudica a independência da OAB}

Submeter-se à prestação de contas perante os órgãos oficiais de fiscalização, em obediência às determinações constitucionais previstas no artigo 70 da Consti-

6 STF, MS 21.797-9, j. 9.3.2000. Vide, nesse sentido, publicação do TCU em que a questão é bem exposta: BRASIL. TCU. Orientaçôes para os Conselhos de Fiscalização das Atividades Profissionais. Brasília: TCU, 2014, p. 30-33.

7 E a jurisprudência também, por mais de uma vez, reconheceu a natureza tributária das contribuiçôes à OAB (STF, RE 138.284-CE e STJ, RE 652554, dentre outros).

8 STJ, Embargos de divergência em REsp 503.252-SC (2003/0151664-0), j. 25.8.2004. 
tuição, é um dever de todos aqueles que administrem recursos de natureza pública, como é o caso da $\mathrm{OAB}$, na forma do que já foi exposto. Uma decorrência dos princípios que regem qualquer Estado Democrático de Direito e os ideais republicanos.

Como já mencionado, não há qualquer possibilidade de essa obrigação gerar vínculos de subordinação e hierarquia, tanto que todos os órgãos e poderes dotados de plena autonomia e independência constitucional a ele se submetem, e não as tiveram mitigada por essa razão. Apenas para ilustrar, o Poder Judiciário, cuja independência é assegurada em cláusula pétrea pelos artigos $2^{\circ}$ e $60, \$ 4^{\circ}$, III da Constituição, presta contas aos sistemas de controle externo, controle interno e ao Conselho Nacional de Justiça, além de submeter-se ao amplo leque de possibilidades de controle social. Nem por isso está com sua independência amesquinhada sob qualquer aspecto. Seria por demais exagerado querer atribuir à $\mathrm{OAB}$, que representa a advocacia, função essencial à Justiça, prerrogativas que nem mesmo o Poder Judiciário tem.?

Ao fazer referência ao artigo 44 do Estatuto da $\mathrm{OAB}$, que assegura não haver vínculo da $\mathrm{OAB}$ com órgãos da administração pública, o ministro Bruno Dantas foi preciso: "O dispositivo serve apenas para afirmar que a OAB é entidade autônoma e independente, não estando subordinada a qualquer órgão da administração pública. Essa ausência de subordinação ou vínculo não significa dizer que ela não está sujeita ao controle do Tribunal de Contas da União. Ausência de vínculo funcional ou hierárquico não é sinônimo de ausência de controle" (voto citado, p. 12).

$\mathrm{A} \mathrm{OAB}$ alega ainda questão processual, referente à suposta "coisa julgada", argumento que foi adequada e corretamente afastado pelo ministro Bruno Dantas em seu voto, e não se trata de tema afeto à área do Direito Financeiro, razão pela qual não pretendo me manifestar. E o que importa efetivamente é o mérito, pois, se a $\mathrm{OAB}$ conseguiu em outros tempos decisões que lhe foram favoráveis, quando não se dava à transparência das contas públicas o merecido destaque, que não seja

9 Nesse sentido, o procurador do Ministério Público de Contas junto ao TCU, Júlio Marcelo de Oliveira, em texto recente, foi claro e preciso em suas palavras: "Ser essencial à Justiça e defender direitos da cidadania, como a liberdade e a própria democracia, não é exclusividade da $\mathrm{OAB}$. $\mathrm{O}$ Ministério Público e a Defensoria Pública compartilham essa mesma nobre missão, e prestar contas ao TCU não lhes retira nada de sua independência e autonomia para exercer seu múnus público com a mais ampla liberdade. Que dizer, então, da própria Justiça e do STF? Guardião máximo da Constituição e fiador da democracia, cumpre ao STF dirimir os mais delicados e decisivos conflitos da República, velar pela ordem democrática e pelo Estado de Direito, ser o depositário fiel da confiança da sociedade na força normativa da Constituição e no império da lei" (OLIVEIRA, Júlio Marcelo. A OAB deve prestar contas ao TCU? Sim. República para todos! Folha de S.Paulo, Seção Tendências/Debates, 2 de junho de 2018, p. A-3. 
este um motivo para nelas se apoiar e com isso manter uma opacidade que não se justifica.

Como se pode constatar, todos os argumentos que tentam sustentar estar a OAB dispensada do dever constitucional de prestar contas ao sistema de fiscalização financeira são frágeis e incapazes de fazer prevalecer essa exceção, que nunca se coadunou com o ordenamento jurídico e os ideais republicanos e democráticos que ela tem o dever de defender.

Recentemente, o presidente do Conselho Federal da OAB, em texto no qual defende a não prestação de contas da $\mathrm{OAB}$ perante o TCU, enumerou vários argumentos, todos na linha do que se analisou há pouco. E formulou pergunta que merece resposta. ${ }^{10}$

Indaga o presidente: "Quem ganharia com a submissão da $\mathrm{OAB}$ - que é transparente, ${ }^{11}$ tem natureza privada e possui mecanismos eficientes de fiscalização e controle - a um órgão da administração pública federal? (...) Quem, então, ganha com isso?".

Resposta: todos ganhariam. Os advogados, a sociedade brasileira, a Constituição, o ordenamento jurídico. O país. O difícil é saber quem perde.

Outra deve ser a questão, que fica agora formulada e aguardando resposta: quem ganharia com a não submissão da $\mathrm{OAB}$ ao TCU?

Por oportuno, as eleições para OAB estão aí. É o momento de os candidatos mostrarem sua posição com relação a esse tema e fazer chegar à sociedade qual $\mathrm{OAB}$ pretendem: uma $\mathrm{OAB}$ defensora dos ideais democráticos, como historicamente sempre foi, e isso inclui o princípio republicano, que tem entre seus pilares a transparência, ou uma OAB que parece ter medo do TCU?

Seria bom ouvi-los a respeito dessas questôes, cujas respostas são importantes para a sociedade brasileira e para aqueles que querem continuar vendo a $\mathrm{OAB}$ defender os interesses da sociedade brasileira, dos princípios constitucionais e dos ideais republicanos, fazendo jus à sua história.

10 LAMACHIA, Cláudio. A OAB deve prestar contas ao TCU? Não. Medida política quer calar a voz crítica da Ordem. Folha de S.Paulo, Seção Tendências/Debates, 2 de junho de 2018, p. A-3.

11 Transparência essa um tanto questionável, pois, como escreveu o ministro Bruno Dantas em recente artigo na Folha de S.Paulo, "a OAB, na contramão dessa tendência, apresenta baixa transparência. Em seu site, por exemplo, não estão disponíveis informações detalhadas sobre suas atividades, receitas, despesas, contratos e empregados. Embora a entidade alegue ser controlada internamente, são ainda opacas as informações prestadas ao público e a seus contribuintes" (Mais transparência para a OAB, publicada em 8 de novembro de 2018, Seção Tendências/Debates, p. A-3). 
A decisão tomada recentemente pelo TCU põe um fim nesse erro histórico que perdura há décadas, causando uma mácula no sistema de fiscalização financeira, que a tem como único órgão não submetido a qualquer fiscalização financeira do poder público, apesar de se valer de recursos públicos para se financiar.

Aguardemos a posição da $\mathrm{OAB}$, e ver se buscará novos "saltos triplos carpados hermenêuticos" para continuar fugindo do TCU. E se assim o fizer, ficará devendo aos advogados e à sociedade brasileira uma explicação convincente para essa atitude.

Haveria ainda muito a argumentar. Razões jurídicas para fundamentar o dever de prestar contas, não somente ao TCU, mas também e principalmente à sociedade brasileira são abundantes. Mas o mais importante é o dever institucional perante nosso Estado Democrático de Direito, e esse caberá à $\mathrm{OAB}$ decidir se deve ou não observar. 
